\title{
Funding and Implementation of National Programme on Immunization in Nigeria: Case Study of Bekwarra Local Government Area, Cross River State
}

\author{
Adie, Hilary Idiege \\ Department of Public Administration, \\ University of Calabar, Calabar-Nigeria \\ Enang, Agnes Ubana \\ Department of Public Administration \\ University of Calabar, Calabar-Nigeria
}

Received: Aug. 9, 2017 Accepted: Jun. 22, 2019 Online published: Jul. 17, 2019

doi:10.5296/jpag.v9i3.15111 URL: https://doi.org/10.5296/jpag.v9i3.15111

\begin{abstract}
This study investigated how funding has affected effective implementation of National Programme on Immunization (NPI) in Bekwarra Local Government of Cross River State, Nigeria from 2003-2016. To achieve this objective, a research hypothesis was formulated. A total of 200 Health workers were randomly selected using survey inferential research design from the population of 320 Health workers in the study area. A well validated Likert type scale instrument called Immunization Related Issues Questionnaire (IRIQ) consisting of 22 items with a reliability index of 0.84 was the instrument for data collection. Data collected from the respondents were subjected to the Chi-Suare statistics to test the hypothesis in the study. The result of the test was significant at 0.05 level and it was concluded that funding significantly influences effective implementation of immunization programme in Bekwarra Local Government Area. The study noted that adequate funds are not provided for effective implementation of National Programme on Immunization (NPI), and whenever funds are provided, it is often mismanaged. Also, it was revealed that non-governmental organization (NGOs) should assist in funding immunization programme by providing logistics and technical equipment for effective programme implementation. It was recommended among others that both the government and health donor agencies should provide adequate funds for effective implementation of immunization programmes. Also, there should be a proper monitoring
\end{abstract}


mechanism for utilization of funds meant for Immunization programmes.

\section{Introduction}

In October 1988, the Federal Government of Nigeria launched a National Health Policy and the bedrock of that policy was Primary Health Care (PHC). According to Akinsola (1993), Primary Health Care is essentially aimed at promoting health, preventing diseases and rehabilitating people to live full normal lives. World Health Organization (WHO, 1998) clearly defined the objectives of PHC as follows: To make health services accessible and available to everyone where they live and work; to tackle the health problems causing the highest morbidity and mortality at a cost that the community can afford; to ensure that whatever technology is used must be within the ability of the community to use effectively and maintain; to ensure that health programmes are successfully implemented by involving the communities in the planning, implementation and evaluation of the programme in the spirit of self-reliance and -determination (WHO, 1987).

According to world Health Organization (WHO, 1987, 1993) and Awosika (2004), to achieve these laudable objectives as enunciated in the PHC, tackling health problems both at the rural and urban setting to curb increasing incidence or mortality and morbidity in a cost-effective approach requires the integration of the immunization component into the larger picture of PHC as the most effective, promising, potent and result-oriented tool that is cost-effective in handling Vaccine Preventable Diseases (VPDs) such as measles, tuberculosis, hopping cough, yellow fever, poliomyelitis, diphtheria, tetanus, neo-natal tetanus, hepatitis $\mathrm{B}$ and Cerebro-spinal meningitis (CSM).

World Health Organization (WHO, 1993) has affirmed that immunization is one of the most powerful and cost-effective weapons of modern medicine. It is accepted worldwide as a top health programme priority among various multilateral, bilateral and non-governmental international development agencies. Immunization programmes are widely accepted and actively promoted as offering programme beneficiaries more substantive diseases prevention benefits such as the reduction of high mortality and morbidity caused by VPDs. Immunization is also time-effective. It guarantees the health of the immunized children and women of child-bearing age than any other modality in the arsenal of modern medicine coupled with its unique capacity to offer the surest and quickest results. It is generally considered to be the easiest to implement programmatically, promote publicly, and defend politically but it, however, remain tragically under-utilized in the world today especially in developing countries as Nigeria.

The National Programme on Immunization (NPI) was initiated to ensure the provision of potent vaccines to states and local government areas with corresponding qualities of needles, syringes, as well as logistics equipment, human, technical and financial supports for effective programe implementation. According to the National Programme on Immunization (NPI, 2003), the Federal Government pursued all strategies in conjunction with the three tiers of government to improve and sustain routine immunization coverage of all citizens to $80 \%$ by the year 2005. The programme was also aimed at achieving quality supplemental activities, reduction of polio transmission by the end of 2003 and total eradication by the year 2005, and 
eliminating maternal and neonatal tetanus by the end of 2005. While progress has been made towards attaining these objectives, full attainment of the objectives and goals are not yet achieved. In fact, the government through the NPI has attempted to put in place annual plan to detect, control and eliminate the occurrence of outbreak of VPDs in all parts of the country through PHC centres and private health facilities.

To achieve the goals of the NPI, resources such as human, material, equipment, time and adequate funding are needed for effective implementation of immunization programmes. Government alone cannot do this, especially in the case of developing nations such as Nigeria. Thus international health donor agencies and Non-governmental organizations (NGOs) such as world Health Organization (WHO), United Nation International Children Emergency Fund (UNICEF), European Union Partnership to Reinforce Immunization Efficiency (EU-PRIME), Global Alliance for Vaccines and Immunization (GAVI) and the organized private sector should unite their efforts and resources to achieve the attainment of the goal of bringing primary health care to the affordable grasp of all. Consequently, this study attempts to assess the available resources, their proper allocation and utilization with a view to identifying the major problem(s) confronting a successful implementation of immunization programme in the Study area (Bekwarra Local Government Area, Cross River State, Nigeria).

\section{Statement of the Problem}

Preventable mortality and morbidity remain a problem in Nigeria especially in the rural sector. Among occurrences of these mortalities and morbidities, Vaccine Preventable Diseases (VPDs) take a sizeable portion. In other words, proper implementation of immunization programmes would lead to a significant reduction of the occurrence of these mortalities and morbidities. This study therefore investigates whether funding affects effective implementation of National Programme on Immunization (NPI) in Bekwarra Local Government Area of Cross River State, Nigeria from 2003-2016. The Expanded Programme on Immunization (EPI) initiated in 1979 was restructured in 1997 and renamed National Programme on Immunization (NPI) as a parastatal of the Federal Ministry of Health by Decree 12 of 1997. The government effort in the implementation of the NPI for the purpose of reduction of childhood morbidity and mortality in Nigeria has not achieved the desired level of success. This is particularly so in the rural communities of Bekwarra Local Government Area due to timelessness of the immunization activities, low level of awareness creation, bureaucratic red-tapism, non-explanation of the implementation process, idiosyncrasies of the government agents in charge of the programme but the greatest impedence to achieving a good measure of the programme objectives may be inadequate funding. Thus, the researcher set out to investigate how funding has affected effective implementation of NPI in Bekwarra between 2003-2009 despite government funding and supports received from donor agencies.

\section{Objective of the Study}

The objective of this study is to investigate how funding has affected the effective implementation of the National Programme on Immunization (NPI) in Bekwarra Local Government Area of Cross River State from 2003-2016. 


\section{Research Hypothesis}

The following hypothesis tested in this study is hereby stated in null form:

- There is no significant relationship between funding and the effective implementation of National Programme on Immunization (NPI) in Bekwarra Local Government of Cross River State, Nigeria.

\section{Literature Review and Theoretical Framework}

The concept of Primary Health Care (PHC) was formulated by the 134 countries that met at the Alma Mata Conference in Russia in September 12, 1978 organized under the auspices of the world Health Organization and the United Nations Children Fund (WHO/UNICEF, 1978). According to the world Health Organization (WHO, 1987), PHC means essential health care based on practical, scientifically-sound and socially acceptable methods and technology, made universally accessible to individuals and families in the community through their full participation and at a cost which the community can afford to maintain at every stage of their development in the spirit of self-reliance and self-determination. PHC forms an integral part of the Nigerian Social and Economic Development. It is the first level of contact of the individual and community in the National Health System, thus bringing health care as close as possible to where people live and work, and constitutes the first elements of a continuing health care process (Akinsola, 1993).

The world health organization (WHO, 1987) specified the aims and objectives of Primary Health Care as follows:

- To make health services accessible and available to everyone wherever they live or work.

- To tackle the health problems causing the highest mortality and morbidity at a cost that the community can afford

- To ensure that whatever technology is used must be within the ability of the community to use effectively and maintain

- To ensure that in implementing health programme, the community must be fully involved in planning the delivery and evaluation of the services in the spirit of self-reliance.

In sum, PHC is essentially aimed at promoting health, preventing disease, curing diseases and rehabilitation. That is, helping people to live fully and normal lives after illness or disability. In the 1999 constitution of the Federal Republic of Nigeria, health is on the concurrent legislative list, by implication; the three tiers of government are vested with the responsibilities to promote health. According to the constitution, Federal, State and Local Governments should support in coordinated manner, a three-tier system of health care viz:

- Primary health care by local governments

- Secondary health care by state governments

- Tertiary health care by federal government

Therefore, PHC shall provide general health services of preventive, curative and 
rehabilitative nature to the population as the entry point of the health care system. It implies therefore that the provision of health care at this level is largely the responsibility of Local Governments with the support of State Ministries of Health within the pivot of National Health Policy. In order to facilitate the monitoring and evaluation aspects of the implementation of PHC objectives, eight components emerged and include:

i. Education concerning prevailing health problems and the methods of preventing and controlling them

ii. Promotion of food supply and proper nutrition

iii. Adequate supply of safe water and basic sanitation

iv. Maternal and child health care including family planning

v. Immunization against the major infectious diseases

vi. Prevention and control of locally endemic diseases

vii. Appropriate treatment of common diseases

viii. Provision of essential drugs (WHO/UNICEF, 1978)

Each of the eight components plays an important role in the provision, maintenance, improvement and promotion of the individual's health status. Still, efforts should be made to create awareness and sensitize the populace concerned. In support of this noble idea, Brenan, Fennesy and Moran (2000) agreed and even declared that PHC can be delivered outside of a hospital setting.

It is worthwhile to note that the mental and dental health care is not presently available in Nigeria due to shortage of personnel. It is also pertinent to mention here that the principle upon which PHC is founded is that health is fundamental human right to be enjoyed by all people in all communities, their social, political and economic status notwithstanding. Egwu (1993) observed that PHC system attempts to address people's "health needs" through an integrated approach utilizing other sectors such as agriculture, education, housing, social and medical services. The integration is designed to encourage active horizontal relationships between people and their local services as opposed to the traditional vertical relationships. PHC is thus very important to health projects/programmes such as the National Immunization Policy (NPI). In other words, NPI could be said to be in line with the goals of the PHC.

In addition, fundamental to PHC system is the realization that the major killer diseases in rural communities in the third world are preventable, and majority of victims of these diseases are children under the age of five (5). Therefore, PHC system encourages countries to shift their National Health Care strategy from urban to rural areas. This is because these childhood killer diseases most severely affect children living in rural areas or locations. To this effect, community health workers are being made use of as key factors in the delivery of preventive health care. The PHC system also gives recognition to local people with little or no formal education who could be trained to perform some basic health services, thus the use of tradition healers or traditional attendants or mid-wives in the villages. They could perform such basic functions such as: 
- Delivery of high quality basic first aid

- Recognition of signs and symptoms of more serious conditions

- Delivery of babies under more hygienic conditions

- Educating their fellow villagers in understanding the disease process in their community

Complimentarily, the PHC system employed the concept of village health committee usually comprises of local residents without regard to political affiliations, sex, age or religion. The committee is expected to actively participate in planning, organizing and managing health care system in the villages.

\section{Funding and Implementation of Health Care Programmes Such as National Programme on Immunization (NPI)}

Egwu (2000) noted that it is now that many developing countries as Nigeria have realized that the primary health programmes are not cheap or free. He also observed that the primary health care programe is threatened by inadequate funding and other challenges. He cited ugly cases where health-related project vehicles are used to serve private needs rather than intended use. This poor state and condition has affected effective implementation of health programmes as the National Programme on Immunization.

In Nigeria, there is declining availability of public funds at various levels of government due to economic recession. The federal health budget of 2016 was only about a fraction of 1981 in real terms. Recurrent expenditure on items such as maintenance of medical supplies and drugs has continued to be reduced, whereas personnel costs have either remained constant or more often increased. The health sector tends to suffer inadequate funding while preference is given to infrastructural development and payment of personnel wages and salaries. Commenting on the ugly development, Makanjuola (1996) argued that the budgetary allocation is a vital indicator of political commitment and the realization of the strategy for health for all depends on the allocation of adequate financial resources, and this was clearly underpinned by Who (1981). The WHO recommended that at least 5\% of a country's annual budget be allocated to health. The WHO target of at least 5\% was achieved for the first and only time in Nigeria in 1995 since 1981. It therefore means that despite the clamour for adequate financial allocation to health especially by WHO, governments have failed to achieve the $5 \%$ budget for the health sector, neither have they even attempted any values close.

According to Okorosobo (1992), the budget of the federal government indicates that health sector expenditures in relation to the total government expenditure fluctuated between 0.56-2.51\% from 1985 to 1991 . Since then, the health sector has been claiming a decreasing proportion of the budget. According to Kwadwo (1985), the PHC received 2\% of the government's health budget. In Cross River State, just as in many other states of the federation, and at federal level, the expected 5\% of the budget recommended by WHO to health care delivery services remains very far from reality. Despite some attempts to improve the health care system and the health status of the people, health care allocation is still not encouraging at all. 
The inadequate and inappropriate funding of the health sector could therefore account for the poor services rendered in the health facilities as well as the continuously decreasing health status of citizens. Apart from inadequate budgetary allocation to the health sector, there is a great inequality between urban and rural areas in access to health care. Analysis of the government's allocation within health sector indicates that increased proportion of the budget have been used to strengthen the curative health care system.

\section{Theoretical Framework}

In this study, Easton's system theory of input and output matrix found in his approach to the analysis of political system in the world politics (1956, Volume 9: 384) is adopted and used as a suitable and appropriate theory to analyze how funding has affected the effective implementation of the National Programme on Immunization (NPI) in Bekwarra Local Government Area of Cross River State, Nigeria from 2003-2016.

Varma (1975) traced the origin of the systems theory in 1920s to the writings of Ludwig Von Bertallanfy, a biologist. He maintained that it was from the Biological sciences that the idea crept into social anthropology as evidenced in the writings of scholars as Durkheim, Radeliffe-Brown and Malinowski. From social anthropology, it was applied by sociologists called Meton and Talcott Parsons. It finally got into use in political science in the wake of the behavioural revolution in the 1950s as found in the works of Easton, Almond and Kaplan.

Systems theory was chosen as an appropriate and suitable theoretical framework in this study because with systems approach, it is possible to study a set of interrelated variables as distinguished from the environment of the set, and of the ways in which this set is maintained under the impact of environmental disturbances (Kaplan, 1967). According Easton (1953, 1965), a political system is the set of interactions through which values are authoritatively allocated for a society. Public policy therefore, is perceived as the response of the political system to the demands emanating from its environment. The political systems receives demands and supports from the environment and converts them into policies and decisions. The environment contains all other systems which together with the political system make up the society as a whole. The economy, ecology, culture and all the conditions and events external to the boundaries of the political system. Inputs to the political system from the environment consists of demand and support. Demands are claims or preferences made individuals and groups on the political system for government action and to satisfy their interest. Support is rendered to certain governmental functionaries when the individuals and groups vote at elections, pay their taxes, obey state law, and accept the decisions and actions of authorities.

\section{Research Methodology}

\section{Research Design}

This study basically is a survey research. Hence, the survey inferential research design has been adopted for the study. Ndiyo (2005) stated that a survey is any procedure which data are systematically collected from a population or a sample through three major methods such as questionnaire, interview or telephone. Israel, Ashipu, Florence and Ebuara (2002) sees a 
survey design as one in which a group of people or items is studied by collecting and analyzing data from only a few people or items considered to be representative of the entire group. The advantages of using this design for this study is that it is cost- and time-effective in examining the distribution of indices and interactions in the population using inference from sample evidence.

\section{Research Area}

The area of study is the Bekwarra Local Government Area of Cross River, Nigeria ith headuaters in Abuochiche. The people generally speak Bekwarra language, it is therefore a monolithic society. The predominant occupation of the people is farming. The Bekwarra Local Government area is made up of ten (10) wards, there are thirty-six (36) health facilities which all carry out routine immunization in their communities. Bekwarra is bounded in the north by Vandeikya in Benue State, in the south by Ogoja Local Government Area. It is also bounded in the west by Yala Local Government Area, and in the east by Obudu Local Government Area. Basically, Bekwarra is located within latitude $6^{0} 47$ North and longitude $8^{0} 48$ and $9^{0}$ East respectively.

\section{Population of the Study}

According to Obinna, Isaac and Sunny (2006), the population of study is the number of target individuals, objects or events that has common characteristics and is of interest to the researcher. The target population in this study is the set of all the three hundred and twenty (320) health workers including males and females in the health facilities in Bekwarra.

\section{Sample and Sampling Procedure}

The sample size adopted for the study is made up of two hundred (200) Health workers randomly distributed in the health centers in each of the ten (10) political wards of Bekwarra Local Government Area. Simple random sampling technique was adopted in selecting the sampled elements. This technique afforded each population element equal opportunity of being included in the sample.

\section{Instrumentation and Data Collection}

The instrument used to gather data for the purpose of testing the research hypothesis was designed by the researcher through ideas from literature reviewed. The instrument is tagged Immunization-Related Issues questionnaire (IRI). The instrument was administered to health workers as stated. The researcher made sure the respondents were properly briefed on the expectation of the uestionnaire and what they should do before being given the instrument to respond to.

\section{Procedure for Data Analysis}

The instrument, Immunization-Relation Issues uestionnaire (IRIQ) administered to the respondents were coded according to coding schedule drawn. Coding translates responses from respondents into mathematically measurable format for statistical analysis to be carried out. Chi $\mathrm{S}$ is used to analyze data collected from the research field. 


\section{Mll Macrothink

\section{Data Analysis and Discussion of Findins}

\section{Test of Hypothesis}

$\mathrm{H}_{0}$ : There is no significant relationship between funding and the effective implementation of National Programme on Immunization (NPI) in Bekwarra Local Government of Cross River State, Nigeria.

$\mathrm{H}_{\mathrm{a}}$ : There is significant relationship between funding and the effective implementation of National Programme on Immunization (NPI) in Bekwarra Local Government of Cross River State, Nigeria.

Table 1. Summary of $17 \mathrm{X} 4$ contingency Chi-S of the influence of funding on immunization in Bekwarra Local Government Area

\begin{tabular}{|c|c|c|c|c|c|c|c|c|c|c|c|}
\hline \multirow{2}{*}{$\begin{array}{l}\text { Items } \\
6\end{array}$} & \multicolumn{2}{|c|}{$\begin{array}{l}\text { Strongly } \\
\text { Agreed }\end{array}$} & \multicolumn{2}{|c|}{ Agreed } & \multicolumn{2}{|c|}{ Disagreed } & \multicolumn{2}{|c|}{$\begin{array}{l}\text { Strongly } \\
\text { disagreed }\end{array}$} & \multirow[t]{2}{*}{$\mathrm{df}$} & \multirow[t]{2}{*}{$\mathrm{X}^{2} \mathrm{Cal}$} & \multirow[t]{2}{*}{$\mathrm{X}^{2} \mathrm{Crit}$} \\
\hline & 137 & (50) & 47 & $(50)$ & 13 & (50) & 3 & $(50)$ & & & \\
\hline 7 & 37 & (50) & 151 & $(50)$ & 11 & $(50)$ & 1 & $(50)$ & & & \\
\hline 8 & 10 & (50) & 23 & $(50)$ & 85 & $(50)$ & 82 & $(50)$ & & & \\
\hline 9 & 10 & (50) & 24 & $(50)$ & 151 & $(50)$ & 15 & $(50)$ & & & \\
\hline 10 & 13 & (50) & 12 & $(50)$ & 113 & $(50)$ & 62 & $(50)$ & & & \\
\hline 11 & 64 & (50) & 108 & $(50)$ & 22 & $(50)$ & 6 & $(50)$ & & & \\
\hline 12 & 23 & (50) & 34 & $(50)$ & 142 & $(50)$ & 1 & $(50)$ & & & \\
\hline 13 & 90 & (50) & 92 & $(50)$ & 16 & $(50)$ & 2 & $(50)$ & & & \\
\hline 14 & 22 & (50) & 161 & $(50)$ & 9 & $(50)$ & 8 & $(50)$ & & & \\
\hline 15 & 17 & (50) & 158 & $(50)$ & 20 & $(50)$ & 5 & $(50)$ & 72 & $3713.27 *$ & 90.53 \\
\hline 16 & 6 & $(50)$ & 21 & $(50)$ & 167 & $(50)$ & 6 & $(50)$ & & & \\
\hline 17 & 5 & $(50)$ & 17 & $(50)$ & 129 & $(50)$ & 49 & $(50)$ & & & \\
\hline 18 & 72 & (50) & 120 & $(50)$ & 5 & $(50)$ & 3 & $(50)$ & & & \\
\hline 19 & 18 & (50) & 22 & $(50)$ & 150 & (50) & 10 & $(50)$ & & & \\
\hline 20 & 5 & (50) & 20 & $(50)$ & 102 & $(50)$ & 73 & $(50)$ & & & \\
\hline 21 & 63 & $(50)$ & 114 & $(50)$ & 17 & $(50)$ & 6 & $(50)$ & & & \\
\hline 22 & 122 & (50) & 71 & $(50)$ & 5 & $(50)$ & 2 & $(50)$ & & & \\
\hline
\end{tabular}

* significant at 0.05 level

Table 1 above shows the result of the Chi-squared analysis of the influence of funding on the effective implementation of the National Programme on Immunization (NPI) in Bekwarra Local Government Area, Cross River State, Nigeria. From the Table, the calculated Chi-squared value of 3713.27 is greater than the critical value of 9053 at $\mathrm{df}=72, \alpha=0.05$. 
Since the calculated Chi-squared value of 371.27 is greater than the critical Chi-squared value of 90.53 at $\mathrm{df}=72, \alpha=0.05$, the null hypothesis which states that there is no relationship between funding and effective implementation of the NPI in Bekwarra Local Government Area is rejected. To this end, the alternative hypothesis which states that there is a relationship between funding and effective implementation of NPI in Bekwarra Local Government Area, Cross River, Nigeria is upheld. In other words, funding is important for the successful implementation of government policy such as the National Programme on Immunization (NPI).

In support of the findings of this study, Makanjuola (1996) observed that the world Health Organization (Who) recommended that at least $5 \%$ of a country annual budget be allocated to health sector. The World Health Organization (Who)'s target of at least 5\% was achieved in Nigeria for the first and only time in 1995. It therefore means that despite the clamour for adequate financial allocation to health, the government of Nigeria has failed to achieve the stipulated target. This could account for the failure of the health policies in the past.

In the same vein, Nyong (2005) in his contribution attributed the problem of implementing health policies in Nigeria especially immunization programmes to persistent under-funding and over-dependence on donor funds. Dr.(Mrs.) J. Aina (2006), one-time commissioner for health in Cross River State in her report supported Nyong (2005) when she recalled that as at 1990, Nigeria attained $80 \%$ coverage but declined as a result poor funding. Okorosobo (1998) observed that this inadequate funding of the health sector could account for poor implementation of the NPI in Bekwarra Local Government, Cross River State. Olu (2003) also observed that there are many problems militating against effective implementation of National Programme on Immunization (NPI) but inadequate funding is said to be a major problem because with provision of adequate funding, all other problems, be it logistics, technical, material, human, infrastructural could be solved with availability of funds.

The foregoing discussion confirms the result of the hypothesis that there is a relationship between funding and effective implementation of the NPI in Bekwarra Local Government Area. Thus, provision of adequate funding has a positive influence on effective implementation of immunization programme. Unfortunately, these funds are inadequate for effective implementation of NPI despite the supports received from international health donors and agencies.

\section{Conclusion}

From the research findings, based on the hypothesis and data analyzed, it was revealed that provision of adequate funding significantly influences effective implementation of NPI in Bekwarra Local Government Area, Cross River State. Also, the research noted that sufficient funds are not provided for effective implementation of the immunization programme, and when funds are provided, it is sometimes mismanaged.

\section{Recommendation}

Based on the findings of this study, the following recommendations are made: 
1. Both the government and health donor/agencies sould provide adequate funding for effective implementation of health policies such as the National Programme on Immunization (NPI) in Bekwarra Local Government Area

2. There sould be a proper monitoring mechanism for the utilization of funds meant for immunization programme or other health programmes in Bekwarra Local Government Area. This would identify problems/lapses and check wastage

3. Community-based organizations and individuals sould be encouraged to assist in funding immunization programme in Bekwarra Local Government Area

4. Stakeholders in the National Programme on Immunization (NPI) office in Bekwarra sould be trained on proper accounting structure and usage of funds meant for immunization programme.

\section{References}

Akinsola, H. A. (1993). Community health and social medicine in medical and nursing practice. Ibadan: 3AM Communications.

Egwu, I. N. (1993). Primary health care (PHC), a system development in Nigeria: Reorientation as a framework of planning and implementation. Lagos: Hamdard Medicine.

Egwu, I. N. (2000). Structural and dynamic perspective on public health, community health, community medicine, primary care and primary health care. Lagos: Hamdard Medicine.

Makanjuola, J. D. A. (1996). Public sectors expenditure on health in Nigeria: A way out. Nigerian Journal of Health Planning and Management, 1(2), 13-17.

Nyong, M. O. (2005). Fundamentals of research in behavioural sciences and humanities: Calabar: wusen publishers.

Okorosobo, T. K. (1992). Nigerian health sector financing and expenditure: health management in developing countries. Lagos: Gabumo Press.

Olu, C. C. (2003). A handbook on primary health care for nurses, midwives and community health nurses. Aba: G. C. Graphics.

Orld Health Organization (1987). Immunization - a chance for every child. Expanded programme on immunization (EPI) update. Geneva: world Health Organization.

Varma, S. P. (1980). Modern political theory: a critique. Delhi: Nutech Photolitho Graphers.

World Health Organization (1993). World Health Organization to strengthen support to member states. Lagos: Gabumo Press.

\section{Copyright Disclaimer}

Copyright for this article is retained by the author(s), with first publication rights granted to the journal.

This is an open-access article distributed under the terms and conditions of the Creative Commons Attribution license (http://creativecommons.org/licenses/by/4.0/). 